\title{
Health Related Quality of Life in a Large Community Sample of Diabetic Patients in a Spanish Region
}

\author{
Olga Monteagudo-Piqueras ${ }^{1}$, Lauro Hernando Arizaleta ${ }^{1}$, Joaquín Palomar \\ Rodríguez $^{1}$, Jordi Alonso ${ }^{2}$ and Monserrat Ferrer Fores ${ }^{2}$ \\ ${ }^{1}$ Department of Health and Social Policy Murcia, Spain
}

${ }^{2}$ IMIM (Hospital del Mar Medical Research Institute), Centro de Investigación Biomédica en Red de Epidemiología y Salud Pública (CIBERESP) and Universitat Pompeu Fabra (UPF), Barcelona, Spain

Correspondence should be addressed to: Olga Monteagudo-Piqueras; olga.monteagudo@carm.es

Received 2 September 2013; Accepted 8 November 2013; Published 31 December 2013

Academic Editor: Karel Kostev

Copyright (C) 2013 Olga Monteagudo-Piqueras, Lauro Hernando Arizaleta, Joaquín Palomar Rodríguez, Jordi Alonso and Monserrat Ferrer Fores. Distributed under Creative Commons CC-BY 3.0

\begin{abstract}
The background of this article is to evaluate Health-Related Quality of Life (HRQoL) of patients with diabetes mellitus living in the community and to assess associated factors. A crosssectional survey through telephone interviews was performed on a sample of patients diagnosed with diabetes mellitus, randomly selected from the Primary Care Database of a Spanish region. The survey included information on sociodemographic and clinical characteristics, HRQoL (SF-12v2), and health-related behaviours. Poor health was defined as a score below the $25^{\text {th }}$ percentile of the corresponding gender and age group of the general population based-norms. Logistic regression models were constructed, separately by gender, to identify the factors associated with poor health. Of 1,187 patients included, only $22.6 \%$ and $31.5 \%$ presented, respectively, poor physical and mental health. The lowest HRQoL was observed in middle-aged women with diabetes, $(\mathrm{OR}=12.0[95 \% \mathrm{CI}=5.6-25.8]$ for poor physical health and 6.9 [95\% $\mathrm{CI}=3.5-13.7]$, for poor mental health). Non-psychiatric comorbidity was independently associated to poor physical health $(\mathrm{OR}=2.5[95 \% \mathrm{CI}=1.5-4.2]$ for female and 1.7 [95\% $\mathrm{CI}=1.0-2.7]$ for male patients). On the other hand, physical activity was a protective factor of both poor physical and poor mental health, among both female and male diabetics (ORs ranging from 0.4 to 0.6 ). HRQoL of community diabetes patients is heterogeneous and particularly worse for female than for male patients. A similar positive association with better HRQoL was found for both genders between physical activity and absence of comorbidity. These results provide very relevant patient-based outcomes to facilitate the identification of vulnerable patients to design specific health programs.
\end{abstract}

Keywords: Diabetes Mellitus, Health-Related Quality of Life, Health Outcomes.

Cite this Article as: Olga Monteagudo-Piqueras, Lauro Hernando Arizaleta, Joaquín Palomar Rodríguez, Jordi Alonso and Monserrat Ferrer Fores (2013), "Health Related Quality of Life in a Large Community Sample of Diabetic Patients in a Spanish Region," Journal of Research in Diabetes, Vol. 2013 (2013), Article ID 445708, DOI: 10.5171/2013.445708 


\section{Introduction}

Diabetes is a chronic disease with a high prevalence worldwide. Estimations for all ages in 2030 are around $4.4 \%$. This would suppose 366 million people with diabetes (Wild et al., 2004). The Region of Murcia, one of Spain's 17 regions, has a crude prevalence of diabetes of $11 \%$ in population aged 20 or more years $(30 \%$ of these undiagnosed) (Valverde et al., 2006), close to the $12.9 \%$ ( $40 \%$ undiagnosed) in U.S. population (Cowie et al., 2009).

Patient management is focused on education and metabolic control to minimize the impact on survival and health-related quality of life (HRQoL). HRQoL - defined as the physical, mental and social aspects of the disease in a person's daily life and its impact on health (Bowling 1991)- has been studied in recent years in diabetic patients (Alonso et al., 2004; Loza et al.,2008). Studies on diabetes have shown that complications and comorbidity have significant impact on patients' HRQoL (UKPDS study Group, 1999; Ose et al., 2009). Furthermore, HRQoL predicts hospital admission in people with diabetes (Li et al., 2009). Thus, HRQoL has become a critical outcome for clinical management of diabetic patients (CDC 2000).

Numerous studies have examined the possible factors associated to the HRQoL of patients with diabetes. However, so far, studies assessing the impact of diabetes on patients' HRQoL addressed this objective with patient-reported diagnose of diabetes within general population samples (Stewart et al., 1989; Ware et al., 2002; Wee et al., 2005; Loza et al., 2008; Esteban-Peña et al., 2010; Sikdar et al., 2010). These studies, without a proven medical diagnosis, showed a similar physical health impairment in diabetes as in other severe chronic conditions such as ischemic heart disease (Alonso et al., 2004). Our main objective was to evaluate the impact of diabetes on HRQoL, taking as a reference the population norms, in a sample of patients with diagnosed diabetes. As a secondary objective, we also assessed the factors associated to HRQoL impact.

\section{Materials and Methods}

In 2006 the Region of Murcia was divided into 6 health areas which covered a population of 1,326,181 inhabitants who were entitled to the National Health Service. Over the year, a cross-sectional survey through telephone interviews was performed on a sample of patients diagnosed with diabetes, randomly selected from the Primary Care Databases.

Inclusion criteria were: patients with registered diagnoses of type 1 diabetes or type 2 diabetes (International Classification of Primary Care, ICPC- 1 code= T90); aged 18 or more years, and living in the community.

The random selection of diabetics was proportional to the number of inhabitants in each health area database. Four further patients of the same age group, gender and area were randomly selected to replace every case if necessary. The sample size was calculated for an expected value of $30 \%$ poor quality of life, with a $95 \%$ confidence interval of $5 \%$ precision. The resulting number of diabetic patients per health area was rounded up to 250 , which meant a total of 1,500 patients.

To achieve the 1,500 participating patients it was necessary to try to contact 2,567 people (replacement ratio of $41.5 \%$ ). The main reasons for replacement were: not answering the phone after a minimum of 4 calls and a maximum of 10 , attempts being held for several days in different time zones (76\%); Poor diagnostic classification (10\%); Death (5\%); and Serious physical $(6 \%)$ or mental (3\%) disability that prevented the interview.

The survey consisted of a structured questionnaire, administered by trained interviewers, with questions grouped into five areas: 1) the Short Form-12 Health Survey (SF-12v2); 2) health-related behaviours such as smoking status, and physical activity in leisure time; 3) diabetes characteristics (treatment and disease duration); 4) health care utilization (hospitalization in the last year and number of visits to primary care during the 
last month); and 5) sociodemographic characteristics (gender, age, marital status and level of studies).

Leisure time physical activity was assessed by the question "Which of the following possibilities best reflects the frequency with which you perform any physical activity?: does not perform, once a month, several times a month or several times a week?" It was dichotomized into 'Sedentary' (formed by the categories "do not perform" or "once a month") and 'Active' (for all other categories). Work physical activity was assessed by the question "Which of the following possibilities best reflects your main activity at work, education center, home (domestic chores), etc?" It was dichotomized into 'Sedentary' (formed by the categories "Sitting most of the day" and "standing most of the day, without having to walk much nor perform high physical efforts") and 'Active' for the other two categories ("Walking, carrying some weight, performing frequent movements that do not require a high physical effort" and "Performing tasks that require a high physical effort"). Age was categorized into 5 groups (18-44, 45-54, 55-64, 65-74 and 75 or more years), smoking status was recorded as non smoker, smoker or former smoker; and diabetes treatment as oral antidiabetics "OAD", insulin, OAD and insulin or only diet and exercise. All other variables were dichotomous.

\section{Health-Realted Quality of Life (HRQoL)}

HRQoL was measured using the SF-12 version 2 (Ware et al., 2002), an abbreviated version of the Short Form-36 Health Survey with only 12 items which considerably reduces respondent burden, making it more suitable for use in large sample sizes (over 500 individuals), (Vilagut et al., 2005). SF-12 covers eight health dimensions: Physical Functioning, Role Physical, Bodily Pain, General Health, Vitality, Social Functioning, Role Emotional and Mental Health. In this study version 2 of the SF-12, which had previously been adapted into Spanish, was used (Alonso et al., 1998). Version 2 of the SF-12 has a greater comparability among linguistic adaptations and uses a five-level response scale for all items, except for those in the Physical Functioning dimension which retained the original 3-point Likert scale. Scores for the two component summaries (physical and mental component summaries, PCS-12 and MCS-12) were calculated using the standardized procedure proposed by the original authors of the questionnaire. Since reference norms are the most recommended interpretation strategy for the SF-12 questionnaire, poor health was defined as a score below the 25th percentile of the corresponding gender and age group of norms. The reference norms used were obtained from a representative sample of general population (noninstitutionalized individuals, aged 18 years or more) from the Region of Murcia, Spain (Monteagudo-Piqueras et al., 2011).

\section{Comorbid Conditions}

Comorbid chronic conditions were searched for in the patients' electronic medical record as diagnoses according to the International Classification of Primary Care (ICPC-1) (Lambers and Wood 1987). Comorbidity assessment was through the adaptation of the Charlson index (Deyo et al., 1992; Romano et al., 1993) for administrative databases.

A summary indicator of the number of conditions was derived from this adapted version of Charlson index after excluding psychiatric disorders. "Non-psychiatric comorbidity" respondents were classified into one of four categories (none, 1, 2, and 3 medical conditions). "Psychiatric comorbidity" was analyzed independently from other medical conditions, due to its differential expected effect on the MCS.

\section{Statistical Analysis}

Study variables were described as sample counts and percentages; differences between men and women were tested using either Fischer's exact test or Chisquared test. Bivariate analyses were performed on the total sample and also separately per gender groups. Accordingly to results of bivariate analysis, separate 
logistic regression models for females and males were built to assess the factors associated with 'poor physical health' and 'poor mental health' (a total of 4 models). For each model, the age variable was expressed taking as a reference the category that was closest to the percentile 25 value in general population (Monteagudo-Piqueras et al., 2011), women and men (preset threshold of poor health). Non-psychiatric comorbidity was entered into the models as a dichotomous variable (having or not any other chronic medical condition). Interactions between independent variables were examined. The analyses were conducted with SPSS $^{\circledR}$ software (version 15.0).

\section{Ethical Aspects}

To ensure confidentiality of information relating to patients, the current data protection law was applied (C. Economic 2006) and a security data base protocol was elaborated. The protocol established who was authorized to consult or work with the data base and a confidentiality agreement was signed by everyone.

Patients received a letter inviting them to take part in the study and giving them information about their rights (access, change or deletion of their data). These letters were sent 3 months before the telephone interview from the Regional Health Council, signed and stamped by the regional health authority.

\section{Results}

From the 1,500 invited patients with diabetes, 1,483 responded to the survey. We excluded 281 for whom no electronic medical records were available, and 15 additional patients with missing data in their responses to the SF12v2. Finally, 1,187 individuals with diabetes (79.1\%) were included in the analyses $(53.6 \%$ women). Table 1 shows the profile of those patients excluded from the analysis ( $\mathrm{n}=$ 296), which were similar to the sample included $(n=1,187)$.

\section{Patient Characteristics}

Table 1 shows the characteristics of patients by gender. Female patients were older $(65.4 \%$ vs. $51.7 \%$ over 65 years of age, $\mathrm{p}<0.000$ ), had lower education level, and reported less physical activity during leisure time $(51.7 \%$ vs. $66.3 \%, \mathrm{p}<0.000)$, and tobacco consumption ( $p<0.001)$ than male patients. Most patients were using OAD treatment only (70.4\%) and $12.8 \%$ only insulin. The percentage of patients treated with OAD and insulin was higher in women than in men $(8.4 \%$ vs. $4.2 \%$, p $<0.001)$. Women reported more often psychiatric comorbidity (19.5\% vs. $11.1 \%$, p <0.001), musculoskeletal problems $(31.0$ vs. 15.8, p <0.000) and two or more associated physical conditions (37.4 \% vs. $28.3 \%$, p < 0.010 ). Only $1.8 \%$ of our patients were born in a country other than Spain.

Table 1. Characteristics of the Sample of Diabetic Patients in the Region of Murcia

\begin{tabular}{|c|c|c|c|c|c|}
\hline & Women & Men & & $\begin{array}{c}\text { Total } \\
\text { included } \\
(\mathrm{n}=1.187)\end{array}$ & $\begin{array}{l}\text { Total excluded } \\
\quad(n=296)\end{array}$ \\
\hline & N (\%) & N (\%) & $\begin{array}{r}P \\
\text { value }\end{array}$ & N (\%) & N (\%) \\
\hline Women & - & - & & $\begin{array}{c}636 \\
(53.5 \%)\end{array}$ & $171(51.4 \%)$ \\
\hline \multicolumn{6}{|l|}{ Age } \\
\hline 18-44 years & $24(3.8 \%)$ & $40(7.3 \%)$ & $\begin{array}{r}<0.00 \\
1 \\
\end{array}$ & $64(5.4 \%)$ & $16(4.9 \%)$ \\
\hline $45-54$ years & $55(8.6 \%)$ & 85 (15.4\%) & & $\begin{array}{c}140 \\
(11.8 \%)\end{array}$ & $27(8.1 \%)$ \\
\hline 55-64 years & $\begin{array}{c}141 \\
(22.2 \%)\end{array}$ & $141(25.6 \%)$ & & $\begin{array}{c}282 \\
(23.8 \%)\end{array}$ & $80(24.0 \%)$ \\
\hline 65-74 years & 225 & $163(29.6 \%)$ & & 388 & $94(28.2 \%)$ \\
\hline
\end{tabular}




\begin{tabular}{|c|c|c|c|c|c|}
\hline & $(35.4 \%)$ & & & $(32.7 \%)$ & \\
\hline 75 or more years & $191(30 \%)$ & $122(22.1 \%)$ & & $\begin{array}{c}313 \\
(26.4 \%)\end{array}$ & $116(34.9 \%)$ \\
\hline \multicolumn{6}{|l|}{ Education } \\
\hline Primary uncompleted & $\begin{array}{c}379 \\
(60.3 \%)\end{array}$ & $210(38.6 \%)$ & $\begin{array}{r}<0.00 \\
1\end{array}$ & $\begin{array}{c}589 \\
(50.2 \%)\end{array}$ & $166(49.7 \%)$ \\
\hline Primary completed & $\begin{array}{c}114 \\
(18.1 \%)\end{array}$ & $117(21.5 \%)$ & & $\begin{array}{c}231 \\
(19.7 \%)\end{array}$ & $62(18.6 \%)$ \\
\hline High school & $\begin{array}{c}118 \\
(18.8 \%)\end{array}$ & $172(31.6 \%)$ & & $\begin{array}{c}290 \\
(24.7 \%)\end{array}$ & $74(22.2 \%)$ \\
\hline Higher education & $18(2.9 \%)$ & $45(8.3 \%)$ & & $63(5.4 \%)$ & $27(8.2 \%)$ \\
\hline Living with a partner & $\begin{array}{c}430 \\
(67.9 \%)\end{array}$ & $466(85.7 \%)$ & $\begin{array}{r}<0.00 \\
1 \\
\end{array}$ & $\begin{array}{c}896 \\
(76.1 \%)\end{array}$ & $231(70.0 \%)$ \\
\hline \multicolumn{6}{|l|}{ Smoking status } \\
\hline Non smoker & $\begin{array}{c}544 \\
(86.1 \%) \\
\end{array}$ & $110(20.1 \%)$ & & $\begin{array}{c}654 \\
(55.5 \%)\end{array}$ & $182(54.5 \%)$ \\
\hline Smoker & $40(6.3 \%)$ & $138(25.3 \%)$ & & $\begin{array}{c}178 \\
(15.1 \%)\end{array}$ & $46(13.9 \%)$ \\
\hline Former smoker & $48(7.6 \%)$ & $298(54.6 \%)$ & & $\begin{array}{c}346 \\
(29.4 \%)\end{array}$ & $98(29.5 \%)$ \\
\hline \multicolumn{6}{|l|}{ Physical activity in leisure } \\
\hline Sedentary & $\begin{array}{c}306 \\
(48.3 \%)\end{array}$ & $185(33.7 \%)$ & $\begin{array}{r}<0.00 \\
1\end{array}$ & $\begin{array}{c}491 \\
(41.5 \%)\end{array}$ & $150(44.9 \%)$ \\
\hline Active & $\begin{array}{c}328 \\
(51.7 \%)\end{array}$ & $364(66.3 \%)$ & & $\begin{array}{c}692 \\
(58.5 \%)\end{array}$ & $179(53.7 \%)$ \\
\hline \multicolumn{6}{|l|}{ Work physical activity } \\
\hline Sedentary & $\begin{array}{c}263 \\
(41.6 \%)\end{array}$ & $215(39.2 \%)$ & 0.406 & $\begin{array}{c}478 \\
(40.5 \%)\end{array}$ & $144(43.1 \%)$ \\
\hline Active & $\begin{array}{c}369 \\
(58.4 \%)\end{array}$ & $333(60.8 \%)$ & & $\begin{array}{c}702 \\
(59.5 \%)\end{array}$ & $180(54.0 \%)$ \\
\hline \multicolumn{6}{|l|}{ Type of treatment for DM } \\
\hline Diet and exercise only & $63(9.9 \%)$ & $59(10.8 \%)$ & $\begin{array}{r}<0.00 \\
1\end{array}$ & $\begin{array}{c}122 \\
(10.3 \%)\end{array}$ & $45(13.4 \%)$ \\
\hline OAD only & $\begin{array}{c}436 \\
(68.8 \%) \\
\end{array}$ & $395(72.3 \%)$ & & $\begin{array}{c}831 \\
(70.4 \%) \\
\end{array}$ & $200(60.1 \%)$ \\
\hline OAD and Insulin & $53(8.4 \%)$ & $23(4.2 \%)$ & & $76(6.4 \%)$ & $25(7.5 \%)$ \\
\hline Insulin only & $\begin{array}{c}82 \\
(12.9 \%) \\
\end{array}$ & $69(12.6 \%)$ & & $\begin{array}{c}151 \\
(12.8 \%)\end{array}$ & $56(16.9 \%)$ \\
\hline \multicolumn{6}{|l|}{ DM duration } \\
\hline$<10$ years & $\begin{array}{c}329 \\
(56.9 \%)\end{array}$ & $302(61.4 \%)$ & 0.152 & $\begin{array}{c}631 \\
(59.0 \%)\end{array}$ & $148(44.5 \%)$ \\
\hline 10 years or more & $\begin{array}{c}249 \\
(43.1 \%)\end{array}$ & $190(38.6 \%)$ & & $\begin{array}{c}439 \\
(41.0 \%)\end{array}$ & $152(45.7 \%)$ \\
\hline \multicolumn{6}{|l|}{ Health care (HC) utilization } \\
\hline $\begin{array}{r}\text { Hospitalization during previous } \\
\text { year }\end{array}$ & $\begin{array}{c}102 \\
(16.1 \%)\end{array}$ & $85(15.5 \%)$ & 0.806 & $\begin{array}{c}187 \\
(15.8 \%)\end{array}$ & $67(20.2 \%)$ \\
\hline $\begin{array}{r}\text { Primary Care visits previous } \\
\text { month }\end{array}$ & $\begin{array}{c}378 \\
(59.4 \%) \\
\end{array}$ & $329(59.7 \%)$ & 0.981 & $\begin{array}{c}707 \\
(59.6 \%)\end{array}$ & $195(58.5 \%)$ \\
\hline \multicolumn{6}{|l|}{ Comorbidity } \\
\hline Mental disorder (1) & $\begin{array}{c}124 \\
(19.5 \%)\end{array}$ & $61(11.1 \%)$ & $\begin{array}{r}<0.00 \\
1\end{array}$ & $\begin{array}{c}185 \\
(15.6 \%)\end{array}$ & - \\
\hline Lipid metabolism (2) & $\begin{array}{c}232 \\
(36.5 \%)\end{array}$ & $194(35.2 \%)$ & 0.649 & $\begin{array}{c}426 \\
(35.9 \%)\end{array}$ & - \\
\hline
\end{tabular}




\begin{tabular}{|c|c|c|c|c|c|}
\hline Musculoskeletal system (3) & $197(31 \%)$ & $87(15.8 \%)$ & $\begin{array}{r}<0.00 \\
1\end{array}$ & $\begin{array}{c}284 \\
(23.9 \%)\end{array}$ & - \\
\hline Cardio or cerebrovascular (4) & $\begin{array}{c}119 \\
(18.7 \%)\end{array}$ & $106(19.2 \%)$ & 0.824 & $225(19 \%)$ & - \\
\hline Hepatic or digestive (5) & $\begin{array}{c}72 \\
(11.3 \%) \\
\end{array}$ & $53(9.6 \%)$ & 0.345 & $\begin{array}{c}125 \\
(10.5 \%)\end{array}$ & - \\
\hline Ophthalmological (6) & $62(9.7 \%)$ & $49(8.9 \%)$ & 0.689 & $111(9.4 \%)$ & - \\
\hline Chronic pulmonary (7) & $36(5.7 \%)$ & $41(7.4 \%)$ & 0.238 & $77(6.5 \%)$ & - \\
\hline Neurological (8) & $29(4.6 \%)$ & $15(2.7 \%)$ & 0.123 & $44(3.7 \%)$ & - \\
\hline Urinary or renal (9) & $26(4.1 \%)$ & $17(3.1 \%)$ & 0.437 & $43(3.6 \%)$ & - \\
\hline Endocrine-metabolic* (10) & $8(1.3 \%)$ & $4(0.7 \%)$ & 0.400 & $12(1 \%)$ & - \\
\hline $\begin{array}{l}\text { Malignant tumour or } \\
\text { metastasis(11) }\end{array}$ & $3(0.5 \%)$ & $2(0.4 \%)$ & 0.400 & $5(0.4 \%)$ & - \\
\hline AIDS (12) & $1(0.2 \%)$ & $1(0.2 \%)$ & 1.000 & $2(0.2 \%)$ & - \\
\hline \multicolumn{6}{|l|}{ Number of chronic disorders } \\
\hline 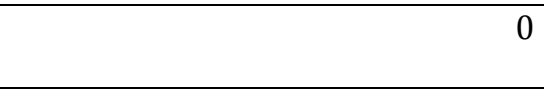 & $\begin{array}{c}202 \\
(31.8 \%)\end{array}$ & $203(36.8 \%)$ & 0.010 & $\begin{array}{c}405 \\
(34.1 \%)\end{array}$ & - \\
\hline 1 & $\begin{array}{c}196 \\
(30.8 \%) \\
\end{array}$ & $192(34.8 \%)$ & & $\begin{array}{c}388 \\
(32.7 \%) \\
\end{array}$ & - \\
\hline 2 & $\begin{array}{c}149 \\
(23.4 \%) \\
\end{array}$ & $102(18.5 \%)$ & & $\begin{array}{c}251 \\
(21.1 \%) \\
\end{array}$ & - \\
\hline 3 & $89(14 \%)$ & $54(9.8 \%)$ & & $143(12 \%)$ & - \\
\hline
\end{tabular}

\section{SF12v2 Scores}

The mean PCS score was $46.1(\mathrm{SD}=10.7)$ in men and $40.0(\mathrm{SD}=12.1)$ in women; while mean MCS was $53.9(\mathrm{SD}=11.2)$ and $46.8(\mathrm{SD}=13.0)$, respectively. Gender differences were statistically significant for both health components $(\mathrm{p}<0.0001)$. Figure 1 presented box plots showing the PCS and MCS distribution ordered in percentiles (p25, p50 and p75) in the sample of patients with diabetes and in the general population. The representative sample of the general population in the region of Murcia (Spain) was composed by 1,707 men and 1,674 women (Monteagudo et al., 2011). While distribution of PCS and MCS in men with diabetes was quite similar to that from the general population, women patients presented lower (worse) PCS and MCS scores than women from general population in certain age groups. The percentage of patients with diabetes who presented poor physical health was $22.6 \%$, below the $25 \%$ expected if it had been distributed as in the general population. By contrast, $31.5 \%$ of patients with diabetes presented poor mental health. The percentage of female patients with poor physical health is higher than the quarter expected in the oldest groups: $37.5 \%$ and $63.6 \%$ in the groups of $18-44$ and 45-54 years, respectively; and this is the case for poor mental health in all age groups. Among male patients, only those in the 55-64 years age group overpassed the quarter with poor physical health (31.9\%), while most age groups have percentages higher than $25 \%$ in poor mental health. 

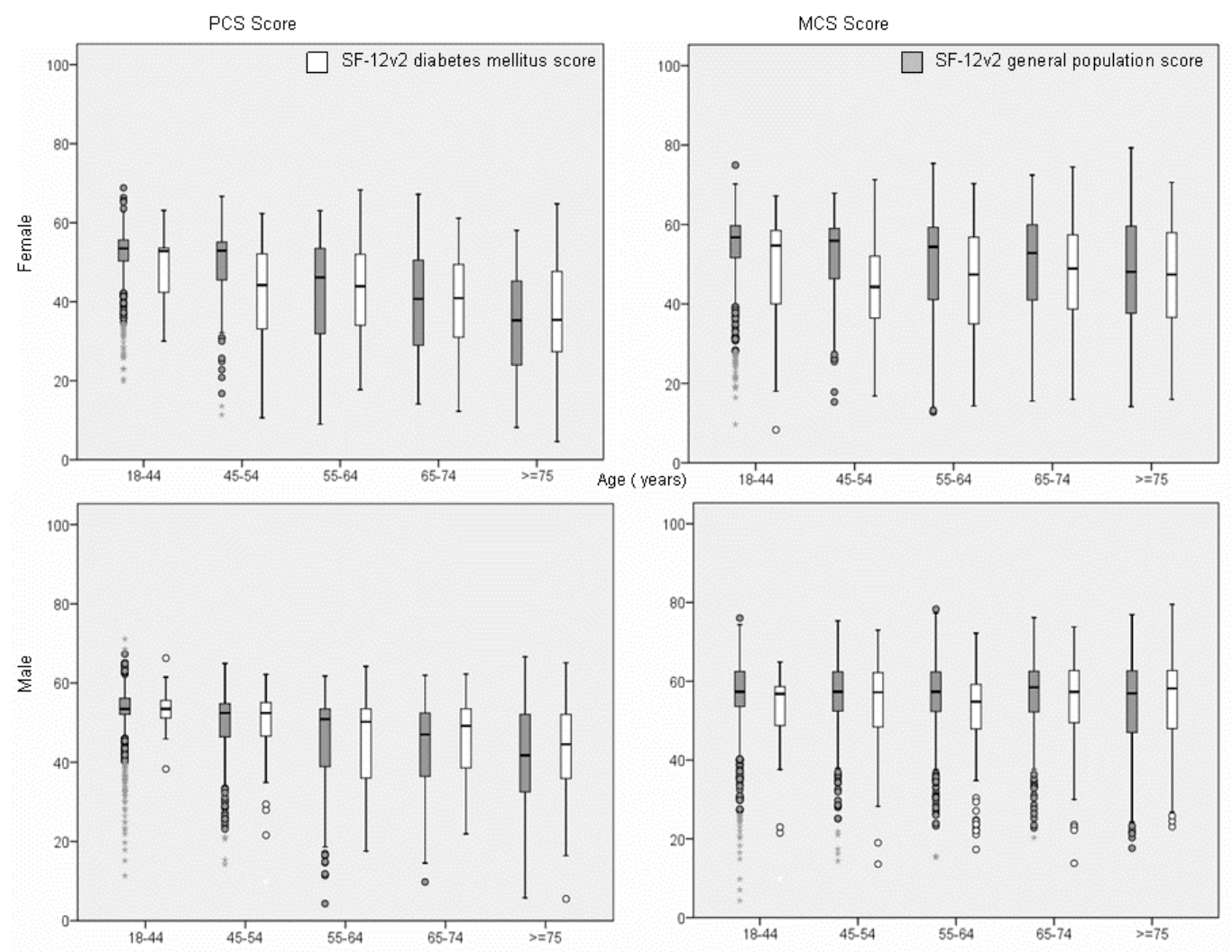

Figure 1: Representation of Physical and Mental Component Sumaries (PCS and MCS) Score of General and Diabetic Population in the Region of Murcia (Spain)

Table 2 shows the results of logistic regression on factors associated with risk of poor health in men and women with diabetes. In women, the youngest ones present a higher risk of poor physical health than the 65-74 years old reference group (chosen as reference because it had a percentage of poor health similar to the general population's p25), while women with 75 or more years had a lower risk of poor physical health. In men, those with more than 64 years had a lower risk of poor physical health than the reference group (45-54 years). Women and men with non-psychiatric comorbidity were more likely to report poor physical health than patients without. Women and men who practiced physical exercise in leisure time or had physical activity at work had a lower risk of poor physical health than sedentary patients. The tobacco habit was significantly associated with physical health only in women, while education level showed significant association only in men. In the mental health model, the group of 65-74 years was chosen as a reference for both men and women, because it had a proportion of poor health similar to p25 in the general population. Women aged 45-54 years had a higher risk of poor mental health than the reference group. The same situation occurs in men, but between the ages of 55-64 years. Women and men engaged in physical activity at work had a lower risk of poor mental health than those who did not. Furthermore, among women, those who practiced physical activity in their leisure time had a lower risk of poor mental health than those who did not. In women, the psychiatric and nonpsychiatric comorbidity was statistically associated with poor mental health, while in men they were not statistically associated. Marital status was significantly associated with mental health only among women, and visits to the general physician only among men. 
Table 2. Impact of Health Determinants for the Physical and Mental Summary Component in Women and Men with Diabetes Mellitus. Results of Logistic Regression Analysis. Region of Murcia. 2006

\begin{tabular}{|c|c|c|c|c|c|c|c|}
\hline \multicolumn{8}{|c|}{ PHYSICAL COMPONENT SUMMARY } \\
\hline & & \multicolumn{3}{|c|}{\begin{tabular}{|c|} 
WOMEN \\
\end{tabular}} & \multicolumn{3}{|c|}{ MEN } \\
\hline & & OR & $(95 \% \mathrm{CI})$ & $p$ & OR & $(95 \% \mathrm{CI})$ & $p$ \\
\hline \multirow[t]{5}{*}{ Age } & $18-44$ years & 4.8 & $(1.7 ; 13.8)$ & 0.004 & 0.8 & $(0.3 ; 2.2)$ & 0.724 \\
\hline & $45-54$ years & 12.0 & $(5.6 ; 25.8)$ & 0.000 & (Ref.) & & 0.000 \\
\hline & $55-64$ years & 1.1 & $(0.6 ; 2.1)$ & 0.638 & 1.3 & $(0.7 ; 2.5)$ & 0.438 \\
\hline & $65-74$ years & (Ref.) & & 0.000 & 0.4 & $(0.2 ; 0.8)$ & 0.010 \\
\hline & $\geq 75$ years & 0.5 & $(0.3 ; 0.9)$ & 0.019 & 0.3 & $(0.1 ; 0.6)$ & 0.002 \\
\hline Non- Psychiatric comorbidity & $\begin{array}{l}\text { No } \\
\text { Yes }\end{array}$ & $\begin{array}{l}\text { (Ref.) } \\
2.5\end{array}$ & $(1.5 ; 4.2)$ & 0.000 & $\begin{array}{l}\text { (Ref.) } \\
1.7\end{array}$ & $(1.0 ; 2.7)$ & 0.040 \\
\hline Physical activity in leisure time & $\begin{array}{l}\text { Sedentary } \\
\text { Active }\end{array}$ & $\begin{array}{l}\text { (Ref.) } \\
0.5\end{array}$ & $(0.3 ; 0.8)$ & 0.006 & $\begin{array}{l}\text { (Ref.) } \\
0.6 \\
\end{array}$ & $(0.4 ; 0.9)$ & 0.020 \\
\hline Work physical activity & $\begin{array}{l}\text { Sedentary } \\
\text { Active }\end{array}$ & $\begin{array}{l}\text { (Ref.) } \\
0.4\end{array}$ & $(0.2 ; 0.6)$ & 0.000 & $\begin{array}{l}\text { (Ref.) } \\
0.5 \\
\end{array}$ & $(0.3 ; 0.8)$ & 0.004 \\
\hline \multirow[t]{3}{*}{ Smoking status } & Non smoker & (Ref.) & & 0.044 & - & & \\
\hline & Smoker & 0.6 & $(0.3 ; 1.5)$ & 0.300 & - & & \\
\hline & Former smoker & 2.2 & $(1.0 ; 4.5)$ & 0.041 & - & & \\
\hline Education & $\begin{array}{l}\text { No } \\
\text { Yes }\end{array}$ & - & & & $\begin{array}{l}\text { (Ref.) } \\
0.4 \\
\end{array}$ & $(0.3 ; 0.7)$ & 0.002 \\
\hline Hospitalization last year & $\begin{array}{l}\text { No } \\
\text { Yes } \\
\end{array}$ & - & & & $\begin{array}{l}\text { (Ref.) } \\
2.7 \\
\end{array}$ & $(1.5 ; 4.6)$ & 0.000 \\
\hline $\mathrm{R}^{2}$ & & & 0.248 & & & 0.16 & \\
\hline \multicolumn{8}{|c|}{ MENTAL COMPONENT SUMMARY } \\
\hline & & \multicolumn{3}{|c|}{\begin{tabular}{|c|} 
WOMEN \\
\end{tabular}} & \multicolumn{3}{|c|}{ MEN } \\
\hline & & OR & $(95 \% \mathrm{CI})$ & $p$ & OR & $(95 \% \mathrm{CI})$ & $p$ \\
\hline \multirow[t]{5}{*}{ Age } & 18-44 years & 2.0 & $(0.7 ; \quad 5.1)$ & 0.175 & 2.0 & $(0.9 ; 4.7)$ & 0.109 \\
\hline & $45-54$ years & 6.9 & $(3.5 ; \quad 13.7)$ & 0.000 & 1.6 & $(0.8 ; \quad 3.0)$ & 0.153 \\
\hline & $55-64$ years & 1.4 & $(0.8 ; \quad 2.3)$ & 0.246 & 2.7 & $(1.6 ; 4.6)$ & 0.000 \\
\hline & $65-74$ years & (Ref.) & & & (Ref.) & & \\
\hline & $\geq 75$ years & 1.2 & $(0.8 ; \quad 2.0)$ & 0.410 & 0.7 & $(0.4 ; 1.2)$ & 0.179 \\
\hline Non- Psychiatric comorbidity & $\begin{array}{l}\text { No } \\
\text { Yes }\end{array}$ & $\begin{array}{l}\text { (Ref.) } \\
1.6 \\
\end{array}$ & $(1.0 ; 2.4)$ & 0.030 & - & & \\
\hline Psychiatric comorbidity & $\begin{array}{l}\text { No } \\
\text { Yes }\end{array}$ & $\begin{array}{l}\text { (Ref.) } \\
1.8 \\
\end{array}$ & $(1.2 ; 2.8)$ & 0.008 & - & & \\
\hline Physical activity in leisure time & $\begin{array}{l}\text { Sedentary } \\
\text { Active }\end{array}$ & $\begin{array}{l}\text { (Ref.) } \\
0.5 \\
\end{array}$ & $(0.4 ; 0.8)$ & 0.003 & - & & \\
\hline Work physical activity & $\begin{array}{l}\text { Sedentary } \\
\text { Active }\end{array}$ & $\begin{array}{l}\text { (Ref.) } \\
0.5 \\
\end{array}$ & $(0.3 ; 0.8)$ & 0.001 & $\begin{array}{l}\text { (Ref.) } \\
0.5 \\
\end{array}$ & $(0.3 ; 0.8)$ & 0.001 \\
\hline \multirow[t]{3}{*}{ Diabetes mellitus treatment } & Diet + exercise & (Ref.) & & 0.044 & - & & \\
\hline & $\mathrm{OAD}$ & 0.7 & $(0.4 ; 1 . .3)$ & 0.270 & - & & \\
\hline & Insulin alone or $\mathrm{v}$ & 1.2 & $(0.6 ; 2.4)$ & 0.571 & - & & \\
\hline Marital status & $\begin{array}{l}\text { Without partner } \\
\text { With partner }\end{array}$ & $\begin{array}{l}\text { (Ref.) } \\
1.7 \\
\end{array}$ & $(1.1 ; 2.6)$ & 0.018 & - & & \\
\hline Primary Care visits & $\begin{array}{l}\text { None } \\
\text { Once or more }\end{array}$ & - & & & $\begin{array}{l}\text { (Ref.) } \\
1.9 \\
\end{array}$ & $(1.2 ; 3.0)$ & 0.007 \\
\hline $\mathrm{R}^{2}$ & & & 0.186 & & & 0.112 & \\
\hline
\end{tabular}




\section{Discussion}

The analysis strategy applied by using the percentile 25 in the general population for each sex and age group as a poor health cut-off point (Figure 1) and the assignment of the age reference category of patients with diabetes closest to the $25 \%$ with poor health, has allowed the direct interpretation of the results using reference standards. Although much information is lost by dichotomizing HRQoL, originally measured as continuous variables (i.e. PCS and MCS), dichotomization into better or worse health than the reference population is one of the several strategies for interpretability proposed by developers of the SF-12. The disadvantage supposed by the loss of information is balanced by the advantage of facilitating the interpretation of results (Ware et al, 2002). This strategy has been applied previously in several studies (Khedmat et al., 2007; Alishiri et al., 2008). On the other hand, the gender perspective applied by analysing separately women and men with diabetes (instead of adjusting by gender), provides information for each gender group beyond showing differences by gender.

It is noticeable that the highest impact of diabetes occurs in middle-aged women (45-54 years). This is the group with the highest likelihood of poor physical and mental health $(\mathrm{OR}=12.0$ and 6.9, respectively), and which would need a special program of action. It is remarkable that the German Diabetes Collaborative Research of Epidemiologic Studies (DIABCORE), (Schunk et al., 2012), also showed the highest HRQoL impact of type 2 diabetes among patients aged 45-54 years. Women have consistently been shown to have worse health status than men in many different populations (Alonso et al., 1998; Hanmer et al., 2006; Emery et al., 2004).

Undoubtedly, the most striking result of our study regarding factors related to HRQL is the protective role of physical activity in patients with diabetes in the Region of Murcia. It is important to remark both the consistency and magnitude (OR close to 0.5 ) of the independent association of physical activity in leisure and in work time with physical and mental health in both genders (except between physical activity in leisure time and mental health in men). Glasgow et al (1997) in a study similar to ours on type 1 diabetes and type 2 diabetes in the U.S., evaluating numerous factors (age, education, income, gender, comorbidity, disease burden, etc.), only identified as a HRQoL explaining factor the level of physical exercise performed. Green et al (2011) showed better physical and mental quality of life among patients with type 2 diabetes exercising regularly, compared with respondents who did not exercise regularly.

A meta-analysis on the effects of different types of exercise on glycemic control, showed that any type of exercise produces small benefits on the control of diabetes in a similar way to how the diet or pharmacological treatment of diabetes do (Snowling and Hopkins 2006). There is also evidence for the contribution to HRQoL improvement in the prescription of physical exercise in physically inactive patients with, or at an increased risk of developing, lifestyle diseases (Sorensen et al., 2010). All this highlights the importance of physical exercise in the health and HRQoL of patients with diabetes, and the role that must be assigned to it in diabetes education programs.

The results of our study on comorbidity support the relevance of this factor in the patient's clinical management. Patients with diabetes who had some other nonpsychiatric conditions diagnosed had worse physical health (and also worse mental health in women) than patients without comorbidity. As hypothesized, women with diabetes and psychiatric illness have poorer mental health than those without an added psychiatric illness. The effect of diabetes complications (Rubin and Peyrot 1999) as well as psychiatric comorbidity (Ali et al., 2010) was evidenced in both systematic reviews. McCollum et al. (2007) added that people with diabetes and depression have poorer mental health and higher cognitive limitations than those with no minor depression. These studies highlight the 
importance of detecting depression in people with diabetes. In fact, even synergistic effects for some combinations of chronic conditions have been described, indicating a higher risk of physical disability than could be expected from their separate effects (Rijken et al ., 2005; Wesseling et al., 2013).

Regarding the variables of treatment, it is worth noting the high proportion of patients with poor health among those medicated with insulin. Of those with insulin alone $34.2 \%$ and $43.4 \%$ presented poor physical and mental heath, respectively, and $30.5 \%$ and $40.4 \%$ for those treated jointly with insulin and OAD. However, the association between type of treatment and HRQL, which was statistically significant in the bivariate analysis (data not shown), disappears when adjusted for other variables in the multivariate analysis. Insulin treatment may be considered as an indicator of disease severity in people with type 2 diabetes (Mata-Cases et al., 2003). Likewise, hospitalization is a severity indicator of the person with diabetes, explaining its association with poor physical health.

Regarding social variables, education is a protective factor in physical health in men. This finding is consistent with previous studies of HRQoL in general population (Robert et al., 2009), and also in patients with diabetes (Connell et al., 1994; GarcíaMendizábal et al., 2009), which can be explained by healthier lifestyles, a higher knowledge about their disease, and a greater ability to relate with their health care providers and to choose and adhere to a treatment (Glasgow et al., 1997). In our study, living with a partner appears as a risk factor for poor mental health in women with diabetes. A previous study showed the predictive ability for HRQoL of the relationship quality, suggesting that it is not the marital status per se but its quality what would explain this association (Trief et al., 2002). Furthermore, the results of our study were consistent with available evidence (Mitra et al., 2004) supporting the potential benefits of smoking cessation in diabetic patients.
McClave et al. (2009) also showed the association between smoking status and HRQoL among a large sample of U.S. adults. Our results should be interpreted taking into account some limitations which deserve comment. An important limitation of our study is, obviously, the lack of differentiation between type 1 and type 2 diabetes due to most diagnoses being coded with the ICPC-1, which assigns the same code to both types of diabetes. Differences in the natural history (age of onset, type of treatment, complications, prognosis, etc.) between both forms of the disease can differentially affect HRQL. However, it should be noted that less than $13 \%$ were medicated with insulin, which suggests that our overall results are more influenced by type 2 diabetes than by type 1 diabetes. Other considerations regarding representativeness are the non inclusion of institutionalized patients and the high percentage of replacements. The first point might imply an overestimation of HRQL, but the second should be minimized because patients were replaced by people of the same age, sex and place of residence.

Secondly, among the possible determinants (García-Mendizábal et al., 2009) of HRQoL in diabetes, neither obesity nor HbA1C were evaluated because clinical and laboratory data were poorly registered in the computerized medical record in 2006, due to the transition period from paper to electronic records that was taking place in the primary health care system of the region. For example, BMI was only collected in $20 \%$ of all studied cases and HbA1c in $32.8 \%$. However, their impact on HRQoL measured with the SF-12 is lower compared to disease-specific questionnaires, since generic HRQoL questionnaires were not usually related to diabetic control markers such as HbA1C. Third, there is no consensus in the cut-off to define poor health based on reference norms. Steward et al. (1988), in the Medical Outcomes Study, established the cut-off in the general population's p20. Taking into account that the negative impact of diabetes on HRQoL was lower than that caused by other chronic medical conditions in previous studies (Alonso et al., 2004; Loza et al., 2008), the selected cut-off point 
was p25 of PCS and MCS in general population.

Even with these limitations, this study provides novel results on HRQoL in female and male patients with diabetes mellitus. To our knowledge, this is the first study to provide evidence on HRQoL impact of diabetes on patients with a proven medical diagnosis, by using as reference the SF$12 \mathrm{v} 2$ population norms. In conclusion, this study shows that the impact of diabetes mellitus on HRQoL is very heterogeneous and markedly different in men and women. However, the positive impact of physical exercise and absence of comorbidity is similar in both genders. HRQoL of most diabetic patients is not so far from their age and gender reference population group. Negative impact is observed mainly in middle-aged women and with associated psychiatric problems, as well as in men with a low education level and who make a higher use of health resources. These results provide very relevant patient-based outcomes to facilitate the identification of vulnerable patients to design specific health programs.

\section{Acknowledgments}

We would like to thank all the people with diabetes mellitus and the numerous colleagues at our institutions who participated or helped in this project altruistically and Aurea Martin for English translation an editing.

\section{Contributions}

O.MP. developed the study concept and design, researched data, and wrote the manuscript. L.H. contributed to develop the study design, analysis and interpretation of data, and reviewed the manuscript. J.P. contributed to develop the study concept, obtained funding, and took responsibility for the integrity of the data. J.A. contributed to the analysis and interpretation of data and critical revision of the manuscript for important intellectual content. M.F. contributed to develop the study design, analysis and interpretation of data and wrote the manuscript.

\section{Declaration of Interest}

Funding for this project comes from public funds allocated in the budget of the Autonomous Community of Murcia to the local Health ministry. The authors do not perform any other paid professional activity related to the subject of study, so they declare no conflict of interest.

\section{Abbreviations \\ (95\%) CI 95\% Confidence Interval \\ HbA1C Glycated hemoglobin \\ HRQoL Health-Related Quality of Life \\ MCS Mental Component Summaries, \\ OR Odds Ratio \\ PCS Physical Component Summaries \\ SD Standard Deviation \\ SF-36 Short Form-36 Health Survey \\ SF12v2 Short Form-12 Health Survey version 2}

\section{References}

Alishiri, G. H., Bayat, N., Fathi Ashtiani, A., Tavallaii, S. A., Assari, S. \& Moharamzad, Y. (2008). "Logistic Regression Models for Predicting Physical and Mental HealthRelated Quality of Life in Rheumatoid Arthritis Patients," Modern Rheumatology, 18 (6) 601-608.

Ali, S., Stone, M., Skinner, T. C., Robertson, N., Davies, M. \& Khunti, K. (2010). "The Association between Depression and Health-Related Quality of Life in People with Type 2 Diabetes: A Systematic Literature Review," Diabetes/Metabolism Research and Reviews, 26 (2) 75-89.

Alonso, J., Ferrer, M., Gandek, B., Ware, J. E. Jr, Aaronson, N. K., Mosconi, P., Rasmussen, N. K., Bullinger, M., Fukuhara, S., Kaasa, S. \& Leplège, A. (2004) . "IQOLA Project Group. Health-related Quality of Life Associated with Chronic Conditions in Eight Countries: Results from the International Quality of Life Assessment (IQOLA) Project," Quality of Life Research, 13 (2) 283-298. 
Alonso, J., Regidor, E., Barrio, G., Prieto, L., Rodríguez, C. \& de la Fuente, L. (1998). "Population Reference Values of the Spanish Version of the Health Questionnaire SF-36," Medicina Clinica (Barc), 111 (11) 410-416.

Bowling, A. (1991). Measuring Health: A Review of Quality of Life Measurement Scale, Open University Press: Buckingham.

Centers for Disease Control and Prevention. (2000). "Measuring Healthy Days," Atlanta, Georgia: CDC. [Online], [Retrieved November 14, 2006], http://www.cdc.gov/hrqol/pdfs/mhd.pdf.

Connell, C. M., Davis, W. K., Gallant, M. P. \& Sharpe, P. A. (1994). "Impact of Social Support, Social Cognitive Variables, and Perceived Threat on Depression among Adults with Diabetes," Health Psychology, 13 (3) 263-273.

Consejería de Economía y Hacienda (2006). 'Orden de la Consejería de Hacienda por la que se Crean Ficheros con Datos de Carácter Personal Gestionados por la Consejería de Sanidad,' BORM. [Online], [Retrieved February 22, 2006], http://www.borm.es/borm/vista/busqued a/ver_sumario.jsf.

Cowie, C. C., Rust, K. F., Ford, E. S., Eberhardt, M. S., Byrd-Holt, D. D., Li, C., Williams, D. E., Gregg, E. W., Bainbridge, K. E., Saydah, S. H. \& Geiss, L. S. (2009). "Full Accounting of Diabetes and Pre-Diabetes in the U.S. Population in 1988-1994 and 2005-2006," Diabetes Care, 32 (2) 287-294.

Deyo, R. A., Cherkin, D. C. \& Ciol, M. A. (1992). "Adapting a Clinical Comorbidity Index for Use with ICD-9-CM Administrative Databases," Journal of Clinical Epidemiology, 45 (6) 613-619.

Emery, C. F., Frid, D. J., Engebretson, T. O., Alonzo, A. A., Fish, A., Ferketich, A. K. et al. (2004). "Gender Differences in Quality of Life among Cardiac Patients," Psychosomatic Medicine, 66 (2) 190-197.
Esteban y Peña, M. M., Hernandez Barrera, V., Fernández Cordero, X., Gil de Miguel, A., Rodríguez Pérez, M., Lopez-de Andres, A. \& Jiménez-García, R. (2010). "Self-Perception of Health Status, Mental Health and Quality of Life among Adults with Diabetes Residing in a Metropolitan Area," Diabetes \& Metabolism, 36 (4) 305-311.

García-Mendizábal, M. J., Carrasco, J. M., Pérez-Gómez, B., Aragonés, N., GuallarCastillón, P., Rodríguez-Artalejo, F., LópezAbente, G. \& Pollán, M. (2009). "Role of Educational Level in the Relationship between Body Mass Index (BMI) and Health-Related Quality of Life (HRQL) among Rural Spanish Women," BMC Public Health. [Online], [Retrieved September 12, 2012], http://www.biomedcentral.com/14712458/9/120.

Glasgow, R. E., Ruggiero, L., Eakin, E. G., Dryfoos, J. \& Chobanian, L. (1997). “Quality of Life and Associated Characteristics in a Large National Sample of Adults with Diabetes," Diabetes Care, 20 (4) 562-567.

Green, A. J., Fox, K. M. \& Grandy, S. (2011). "Impact of Regular Exercise and Attempted Weight Loss on Quality of Life among Adults with and without Type 2 Diabetes Mellitus," Journal of Obesity. [Online], [Retrieved September 11, 2012], http://dx.doi.org/10.1155/2011/172073.

Hanmer, J., Lawrence, W. F., Anderson, J. P., Kaplan, R. M. \& Fryback, D. G. (2006). "Report of Nationally Representative Values for the Noninstitutionalized US Adult Population for 7 health-Related Quality-of-Life Scores," Medical Decision Making, 26 (4) 391-400.

Khedmat, H., Karami, G. R., Pourfarziani, V., Assari, S., Rezailashkajani, M. \& Naghizadeh, M. M. (2007). "A Logistic Regression Model for Predicting HealthRelated Quality of Life in Kidney Transplant Recipients," Transplantation Proceedings, 39 (4) 917-922. 
Lamberts, H. \& Wood, M. (1987). ICPC: International Classification of Primary Care, Oxford: Oxford University Press.

Li, C. L., Chang, H. Y. \& Lu, J. R. (2009). "Health-Related Quality of Life Predicts Hospital Admission within 1 Year in People with Diabetes: A Nationwide Study from Taiwan," Diabetic Medicine, 26 (10) 10551062.

Loza, E., Abásolo, L., Jover, J. A., Carmona, L. \& EPISER Study Group. (2008). "Burden of Disease across Chronic Diseases: A Health Survey that Measured Prevalence, Function, and Quality of Life," The Journal of Rheumatology, 35 (1) 159-165.

Mata Cases, M., Roset Gamisans, M., Badia Llach, X., Antonanzas Villar, F. \& Ragel Alcazar, J. (2003). "Effect of Type-2 Diabetes Mellitus on the Quality of Life of Patients Treated at Primary Care Consultations in Spain," Atencion Primaria, 31(8) 493-499.

McClave, A. K., Dube, S. R., Strine, T. W. \& Mokdad, A. H. (2009). "Associations between Health-Related Quality of Life and Smoking Status among a Large sample of U.S. Adults," Preventive Medicine, 48 (2) 173-179.

McCollum, M., Ellis, S. L., Regensteiner, J. G., Zhang, W. \& Sullivan, P. W. (2007). "Minor Depression and Health Status among US Adults with Diabetes Mellitus," The American Journal of Managed Care, 13 (2) 65-72.

Mitra, M., Chung, M. C., Wilber, N. \& Klein Walker, D. (2004). "Smoking Status and Quality of Life: A Longitudinal Study among Adults with Disabilities," American Journal of Preventive Medicine, 27 (3) 258-260.

Monteagudo Piqueras, O., Hernando Arizaleta, L. \& Palomar Rodríguez, J. A. (2011). "Population Based Norms of the Spanish Version of the SF-12V2 for Murcia (Spain)," Gaceta Sanitaria, 25 (1) 50-61.
Ose, D., Wensing, M., Szecsenyi, J., Joos, S., Hermann, K. \& Miksch, A. (2009). "Impact of Primary Care-Based Disease Management on the Health-Related Quality of Life in Patients with Type 2 Diabetes and Comorbidity," Diabetes Care, 32 (9) 15941596.

Rijken, M., van Kerkhof, M., Dekker, J. \& Schellevis, F. G. (2005). "Comorbidity of Chronic Diseases: Effects of Disease Pairs on Physical and Mental Functioning," Quality of Life Research, 14 (1) 45-55.

Robert, S. A, Cherepanov, D., Palta, M., Dunham, N. C., Feeny, D. \& Fryback, D. G. (2009). "Socioeconomic Status and Age Variations in Health-Related Quality of Life: Results from the National Health Measurement Study," The Journal of Gerontology Series B: Psychological Sciences and Social Sciences 64 (3) 378-389.

Romano, P. S., Roos, L. L. \& Jollis, J. G. (1993). "Adapting a Clinical Comorbidity Index for Use with ICD-9-CM Administrative Data: Differing Perspectives," Journal of Clinical Epidemiology, 46 (10) 1075-1079.

Rubin, R. R., Peyrot, M. (1999). "Quality of Life and Diabetes," Diabetes Metab Res Rev, 15 (3) 205-218.

Schunk, M., Reitmeir, P., Schipf, S., Völzke, H., Meisinger, C., Thorand, B., Kluttig, A., Greiser, K. H., Berger, K., Müller, G., Ellert, U., Neuhauser, H., Tamayo, T., Rathmann, W. \& Holle, R. (2012). "Health-Related Quality of Life in Subjects with and without Type 2 Diabetes: Pooled Analysis of Five Population-Based Surveys in Germany," Diabetic Medicine, 29 (5) 646-653.

Sikdar, K. C., Wang, P. P., MacDonald, D. \& Gadag, V. G. (2010). "Diabetes and its Impact on Health-Related Quality of Life: A Life Table Analysis," Quality of Life Research, 19 (6) 781-787. 
Snowling, N. J .\& Hopkins, W. G. (2006). "Effects of Different modes of Exercise Training on Glucose Control and Risk Factors for Complications in Type 2 Diabetic Patients: A Meta-Analysis," Diabetes Care; 29 (11) 2518-2527.

Sorensen, J., Sorensen, J. B., Skovgaard, T., Bredahl, T. \& Puggaard, L. (2010). "Exercise on Prescription: Changes in Physical Activity and Health-Related Quality of Life in Five Danish Programmes," European Journal of Public Health, 21 (1) 56-62.

Stewart, A. L., Hays, R. D. \& Ware, J. E. Jr. (1988). "The MOS Short-Form General Health Survey. Reliability and Validity in a Patient Population," Medical Care, 26 (7) 724-735.

Stewart, A. L., Greenfield, S., Hays, R. D., Wells, K., Rogers, W. H., Berry, S. D., McGlynn, E. A. \& Ware, J. E. Jr. (1989). "Functional Status and Well-Being of Patients with Chronic Conditions. Results from the Medical Outcomes Study," JAMA, 262 (7) 907-913.

Trief, P. M., Wade, M. J., Britton, K. D. \& Weinstock, R. S. (2002). "A Prospective Analysis of Marital Relationship Factors and Quality of Life in Diabetes," Diabetes Care, 25 (7) 1154-1158.

U.K. Prospective Diabetes Study Group (1999). "Quality of Life in Type 2 Diabetic Patients is Affected by Complications but not by Intensive Policies to Improve Blood Glucose or Blood Pressure Control (UKPDS 37)," Diabetes Care, 22 (7) 1125-1136.

Valverde, J. C., Tormo, M. J., Navarro, C., Rodríguez-Barranco, M., Marco, R., Egea, J. M., Pérez-Flores, D., Ortolá, J. B., GonzálezSicilia, L., Tébar, J., Sánchez-Pinilla, M., Flores, M. \& Cava, J. (2006). "Prevalence of Diabetes in Murcia (Spain): A Mediterranean Area Characterised by Obesity," Diabetes Research and Clinical Practice, 71 (2) 202-209.
Vilagut, G., Ferrer, M., Rajmil, L., Rebollo, P., Permanyer-Miralda, G., Quintana, J. M., Santed, R., Valderas, J. M., Ribera, A., Domingo-Salvany, A. \& Alonso, J. (2005). "The Spanish Version of the Short Form 36 Health Survey: A Decade of Experience and New Developments," Gaceta Sanitaria, 19 (2) $135-150$.

Ware, J. E., Kosinski, M., Turner-Bowker, D. M. \& Gandek, B. (2002). 'How to Score Version 2 of the SF-12® Health Survey (With a Supplement Documenting Version 1),' Lincoln, RI: QualityMetric Incorporated.

Wee, H. L., Cheung, Y. B., Li, S. C., Fong, K. Y. \& Thumboo, J. (2005). "The Impact of Diabetes Mellitus and Other Chronic Medical Conditions on Healthrelated Quality of Life: Is the Whole Greater than the Sum of its Parts?," Health Qual Life Outcomes. [Online], [Retrieved November 11 , http://www.hqlo.com/content/3/1/2. 2010],

Wesseling, J., Welsing, P. M., BiermaZeinstra, S. M., Dekker, J., Gorter, K. J., Kloppenburg, M., Roorda, L. D. \& Bijlsma, J. W. (2013). "Impact of Self-Reported Comorbidity on Physical and Mental Health Status in Early Symptomatic Osteoarthritis: The CHECK (Cohort Hip and Cohort Knee) study. Rheumatology (Oxford)," Rheumatology, 52 (1) 180-188.

Wild, S., Roglic, G., Green, A., Sicree, R. \& King, H. (2004). "Global Prevalence of Diabetes: Estimates for the Year 2000 and Projections for 2030," Diabetes Care, 27 (5) 1047-1053. 